\title{
Do public health services in Egypt help women exercise their reproductive rights?
}

Nahla G. Abdel-Tawab

Population Council

Follow this and additional works at: https://knowledgecommons.popcouncil.org/departments_sbsr-rh

Part of the Demography, Population, and Ecology Commons, Family, Life Course, and Society Commons, International Public Health Commons, Maternal and Child Health Commons, and the Women's Health Commons How does access to this work benefit you? Let us know!

\section{Recommended Citation}

Abdel-Tawab, Nahla G. 2013. "Do public health services in Egypt help women exercise their reproductive rights?" presentation at the International Conference on Family Planning, Addis Ababa, Ethiopia, 14 November. 


\section{Do Public Health Services in Egypt Help Women Exercise their Reproductive Rights?}

\section{Nahla Abdel-Tawab}

Population Council

Cairo, Egypt
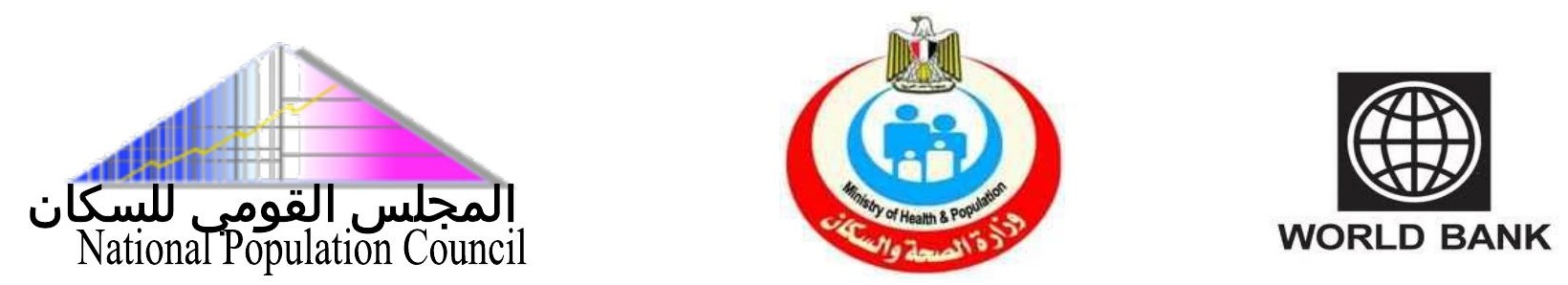


\section{Co-authors}

- Dr. Tamer Rabie

- Dr. Sally Saher

- Ms. Zuzana Boehmova

- Ms. Loraine Hawkins

- Dr. Atef El-Shitany
World Bank Population Council World Bank World Bank Ministry of Health and Population 


\section{Background}

- Total population: 84 million

- Population under 30 years: 63\%

- Population living < \$2/day:25-40\%

- Maternal mortality ratio: 57/ 100,000

- Under five mortality rate: $28 / 1000$

- Neonatal mortality rate: $16 / 1000$

- HIV prevalence rate: <0.01 (general pop)

- Contraceptive prevalence rate: $60 \%$

- FP discontinuation in first 12 months:26\% 


\section{Background}

- Egypt has gone through major political transitions over the last three years with impact on FP program and reproductive rights.

- Family planning (FP) services are widely available in Egypt and awareness of family planning is high

- Contraceptive prevalence rates have been stalling at 60 percent.

- Stalled fertility and high discontinuation rates raise questions about quality of FP services and women's awareness of their reproductive rights. 


\section{Objective}

- The project aimed at identifying factors that prevent Egyptian couples from attainment of their reproductive goals using a rights-based, gender-sensitive analysis of FP service demand and supply.

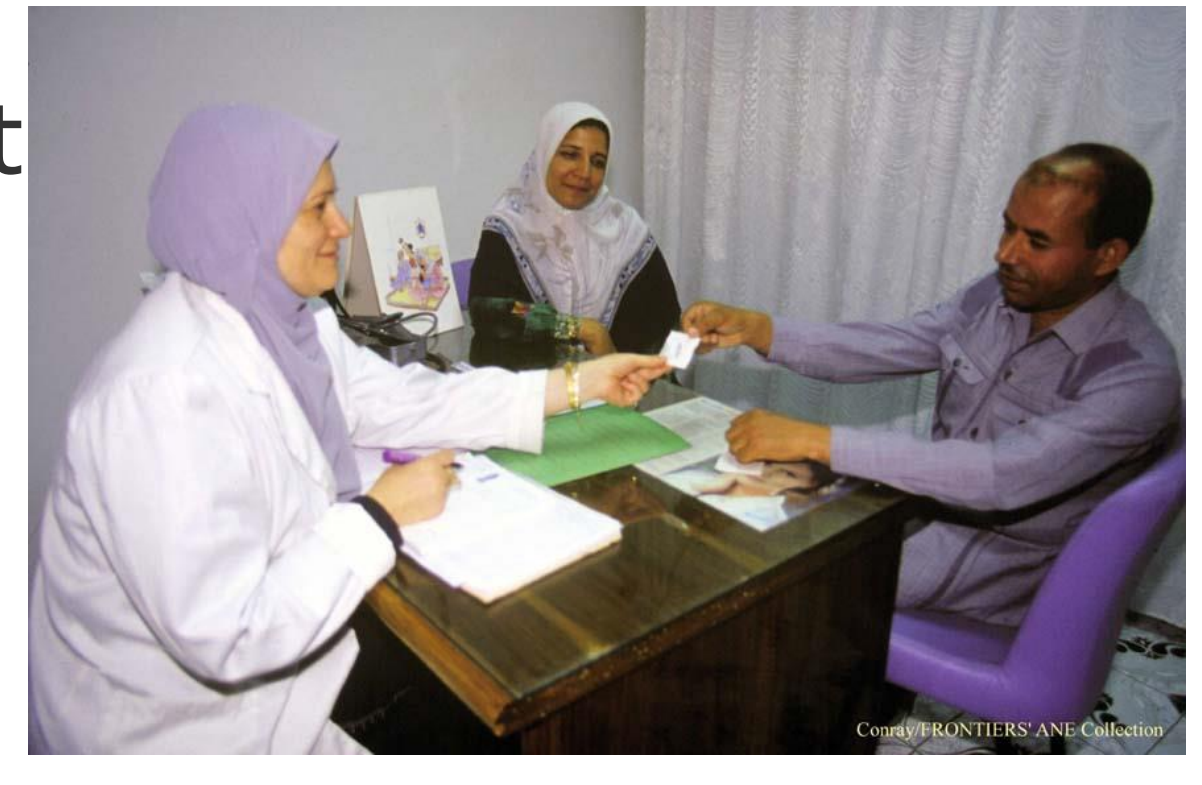




\section{Methodology}

$>$ Situation analysis

- Clinic inventory (40 clinics)

- Structured interviews with service providers $(n=216)$

- Exit interviews with clients $(n=481)$

- In-depth interviews with managers / supervisors $(n=20)$

$>$ Community assessment

o FGDs with married women (18-24 and 25$35)$, husbands, mothers in law $(n=16)$. 


\section{Study Governorates}

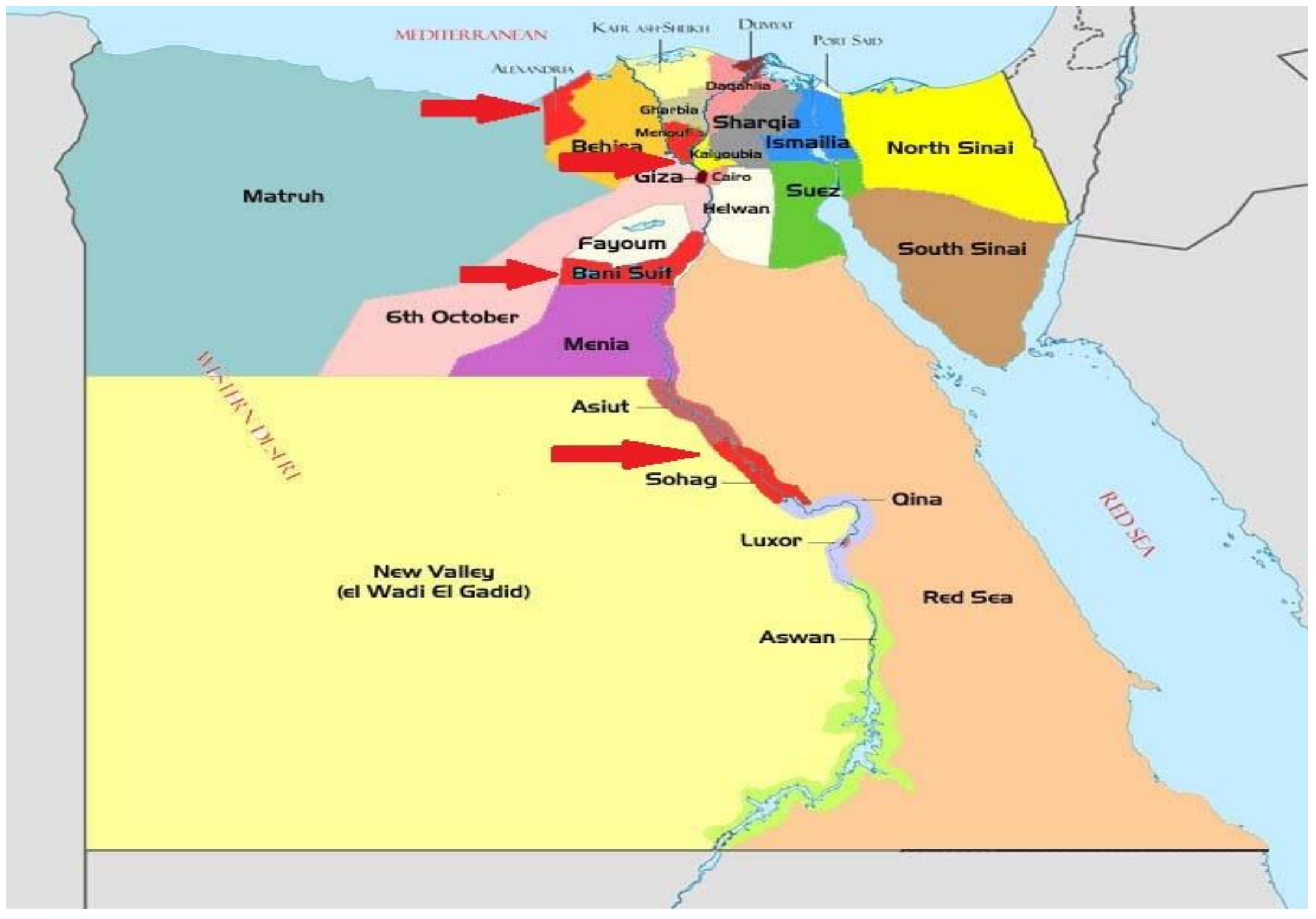




\section{Analysis focused on six aspects of clients' rights:}

$>$ Clinic /provider readiness

$>$ Accessibility and affordability

$>$ Privacy and confidentiality

$>$ Choice and autonomy

$>$ Informed decision-making

$>$ Right to complain 


\section{Clinic/provider readiness}

$>$ Clinics were 'ready' in terms of infrastructure, basic lab services, FP equipment and supplies.

$>42 \%$ of clinics did not have a female doctor

$>43 \%$ of providers received FP training in last 12 months

> Staff turnover was described as an obstacle to achieving client's rights

"Doctors don't stay long enough in our clinics .. by the time they get trained a new doctor comes in..."

(Official in Sohag) 


\section{Clinic/provider readiness}

$>$ Service providers' knowledge was deficient on certain aspects.

- $59 \%$ of providers would recommend emergency contraceptive pills (ECP) to couples who had sex while not using FP

- $33 \%$ of providers knew the three criteria of Lactational Amenorrhea Method (LAM)

- $37 \%$ of providers knew that ovulation returns within 1-2 weeks after an abortion 


\section{Clinic / provider readiness}

- Some services are offered on paper but not in practice

$>$ Premarital counseling services are not taken seriously by providers or communities.

$>$ Services for treatment of infertility do not exist at the village level. 


\section{Accessibility/affordability}

$>$ Services were largely accessible and affordable

$>67 \%$ of clients walked to the clinic and arrived in less than 20 minutes.

> 98 percent of clients paid 5 LE or less for services or transportation 


\section{Accessibility/affordability}

$>$ Young married women have limited access to FP services or choice to delay first pregnancy

$>52 \%$ of providers agree to provide FP to an 18 year old wife who wants to delay her first pregnancy

$>44 \%$ of Raedat Rifyat visit recently married women

$>$ Families do not approve of delaying first pregnancy

"If a month goes by after her wedding and she is not pregnant, we begin to worry and try to find out if something is wrong with him or her"

(Mother in law, Alexandria ) 


\section{Privacy and Confidentiality}

$>$ In $70 \%$ of clinics FP counseling and exam took place in the same room, with curtain separating.

$>30 \%$ of clients said they were asked if they would accept a home visit.

$>98 \%$ of clinics had client files stored in a private place.

$>13$ percent of providers indicated that husbands / relatives were allowed to see client's medical file 


\section{Choice and autonomy}

$>90 \%$ of clinics had three or more FP methods (combined pills, mini pills, IUDs injectables and condoms).

$>$ Subdermal implants and emergency contraceptive pills were present in less than $5 \%$ of facilities.

$>67 \%$ of clients said they chose the method themselves

$>15 \%$ of clients made the decision about the method during physical examination

$>$ Women who use contraception without their husband's permission are at risk of divorce.

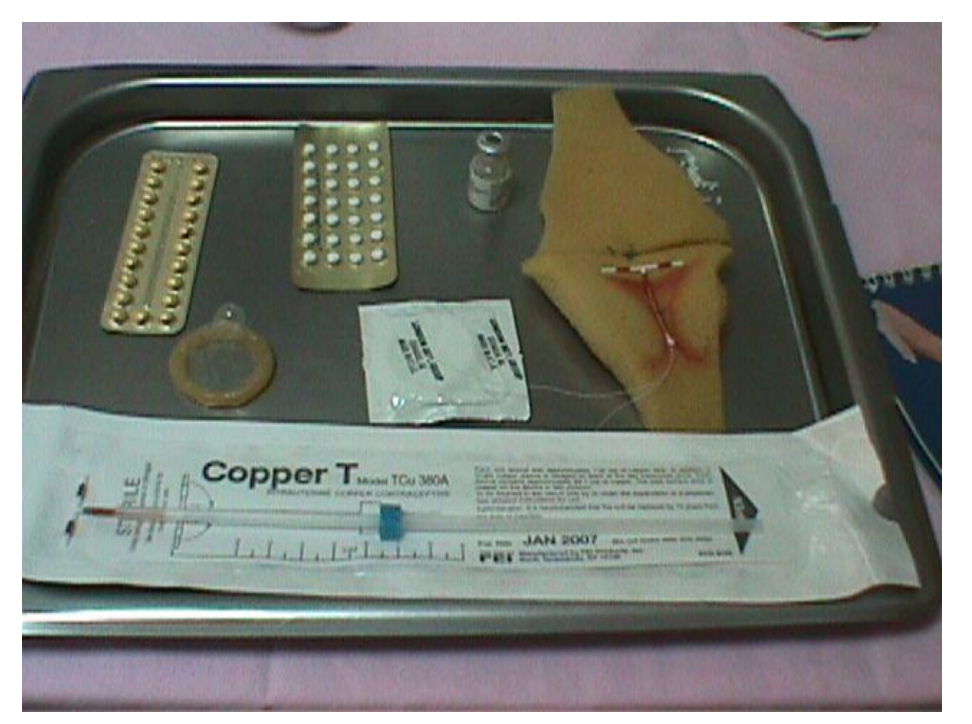




\section{Choice and autonomy}

$>28 \%$ of clients indicated that they were asked about husband approval before receiving a method.

$>52 \%$ of providers indicated the presence of specific target number of IUDs, however program managers confirmed that targets have been abolished.

$>$ Abolishing of client/method targets has had a negative impact on the program as providers are now reluctant to insert IUDs. 


\section{Informed decision making}

$>$ Clients received little information that would enable them to make informed decisions

$>9 \%$ of clients were told how the method works

$>27 \%$ were told about method effectiveness

> Less than half (44\%) were told about sideeffects.

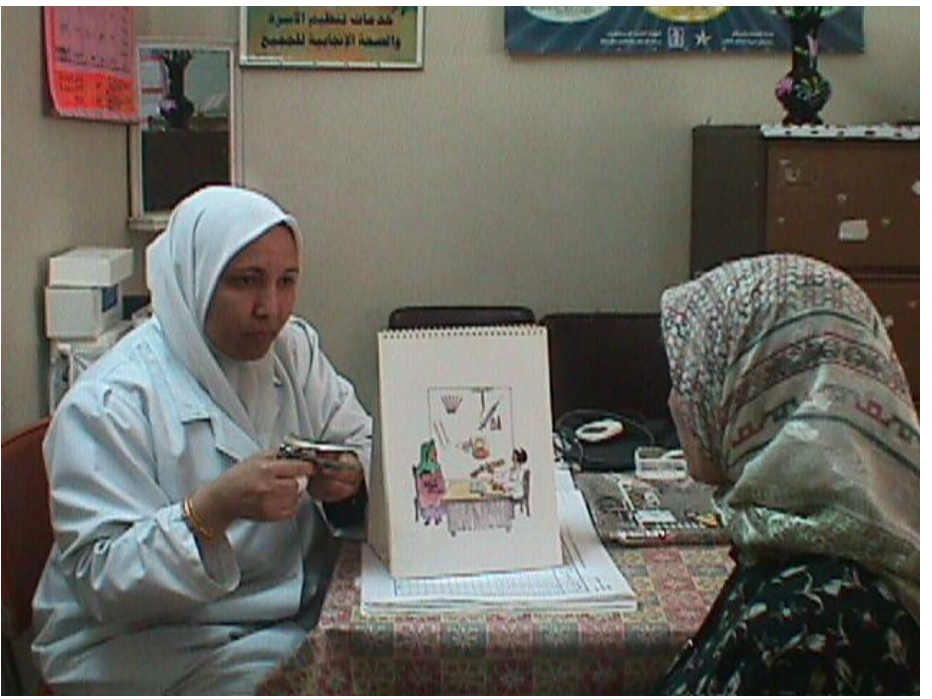




\section{Right to complain}

$>3 \%$ of providers mentioned the right of the client to complain as one of the client's rights

$>12 \%$ of providers mentioned the presence of a form for measuring client's satisfaction

$>$ None of the providers mentioned client satisfaction as one of the criteria to assess their performance. 


\section{Right to complain}

$>$ Husbands, wives \& Mothers in law did not know where to go in case of a complaint and were not sure that their complaint would be taken seriously by officials.

$>$ When they have a complaint most clients prefer 'exit' to 'voice' mechanisms (i.e. by choosing to go to a private clinic).

" It is possible that someone would want to complain, but if you do they will never take your side, .. they will always tell you that you are wrong..."

(Wife in Beni Suef) 


\section{Conclusion}

$>$ Services are largely accessible to older married clients at an affordable price.

> Several gaps exist with regard to protection of client's rights to autonomy, choice, informed decision making, privacy and confidentiality.

$>$ A need for rights-based training of managers and service providers

$>$ A performance based reward system that takes account of clients' perspective

$>$ Empowerment of clients to demand their reproductive rights and to be engaged in quality assurance. 


\section{Thank You}

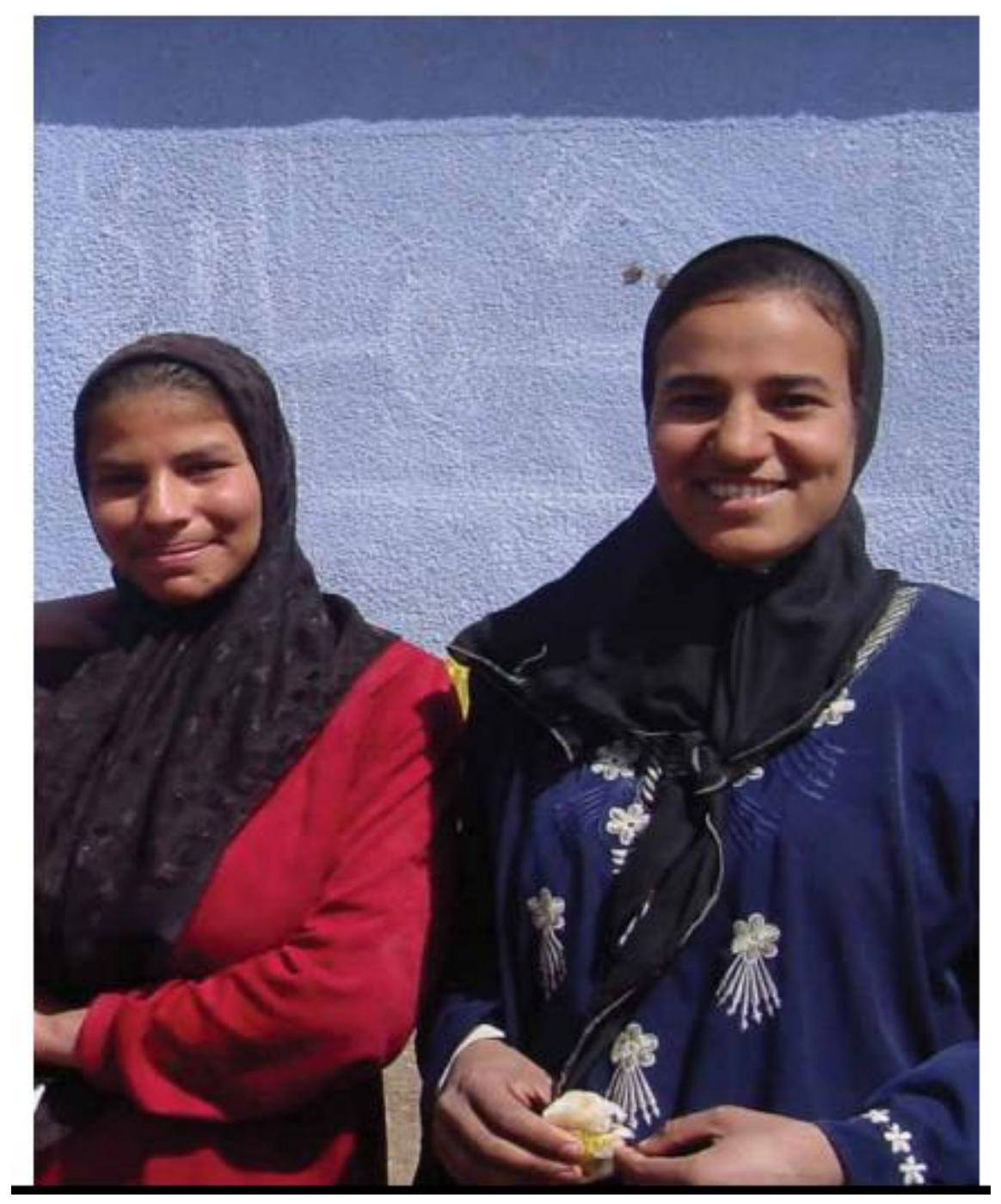

